\title{
Assessment of Motor Units in Neuromuscular Disease
}

\author{
Robert D. Henderson ${ }^{1}$ - Pamela A. McCombe ${ }^{1}$
}

Published online: 6 September 2016

(C) The American Society for Experimental NeuroTherapeutics, Inc. 2016

\begin{abstract}
The motor unit comprises the anterior horn cell, its axon, and the muscle fibers that it innervates. Although the true number of motor units is unknown, the number of motor units appears to vary greatly between different muscles and between different individuals. Assessment of the number and function of motor units is needed in diseases of the anterior horn cell and other motor nerve disorders. Amyotrophic lateral sclerosis is the most important disease of anterior horn cells. The need for an effective biomarker for assessing disease progression and for use in clinical trials in amyotrophic lateral sclerosis has stimulated the study of methods to measure the number of motor units. Since 1970 a number of different methods, including the incremental, F-wave, multipoint, and statistical methods, have been developed but none has achieved widespread applicability. Two methods (MUNIX and the multipoint incremental method) are in current use across multiple centres and are discussed in detail in this review, together with other recently published methods. Imaging with magnetic resonance and ultrasound is increasingly being applied to this area. Motor unit number estimates have also been applied to other neuromuscular diseases such as spinal muscular atrophy, compression neuropathies, and prior poliomyelitis. The need for an objective measure for the assessment of motor units remains tantalizingly close but unfulfilled in 2016.
\end{abstract}

Robert D. Henderson

robert.henderson@health.qld.gov.au

1 Department of Neurology, Royal Brisbane \& Women's Hospital and University of Queensland Centre for Clinical Research, Herston, Brisbane 4006, Australia
Keywords ALS · amyotrophic lateral sclerosis $\cdot$ motor unit . biomarker · electrophysiology

\section{Introduction}

This review will discuss motor units, and focus on the electrophysiological assessment of motor units relevant to neurotherapeutics. In particular, there is a need for a measurement of the number of motor units as an endpoint for clinical trials. Amyotrophic lateral sclerosis (ALS) is the disease where a reliable method is lacking, which has stimulated the development of the assessment of motor units; however, the motor unit measures can also be applied to other disorders of motor nerves. The review will focus on methods that are being actively used in human studies and the use of these measures in clinical trials.

\section{Anatomy of Motor Units}

The lower motor neuron is the peripheral pathway for motor nerves and can also be described as the motor unit. The motor unit, as defined by Sherrington [1], includes the anterior horn cell, motor nerve, neuromuscular junction, and the muscle fibers supplied by the individual anterior horn cell (Fig. 1) [2]. Different muscles have different numbers of motor units. Not all motor units are functional and so the number of motor units measured by functional tests may be less than the total number of motor units that could be measured by anatomic methods. The number of motor units appears to decline with age, and may vary greatly among people [1, 3-5].

The motor units in muscles supplied by the median and ulnar nerves have been the most studied and there are also studies of muscles supplied by the peroneal nerve in the foot 
Fig. 1 The components of a motor unit from the anterior horn cell in the spinal cord through to the respective muscle fibers

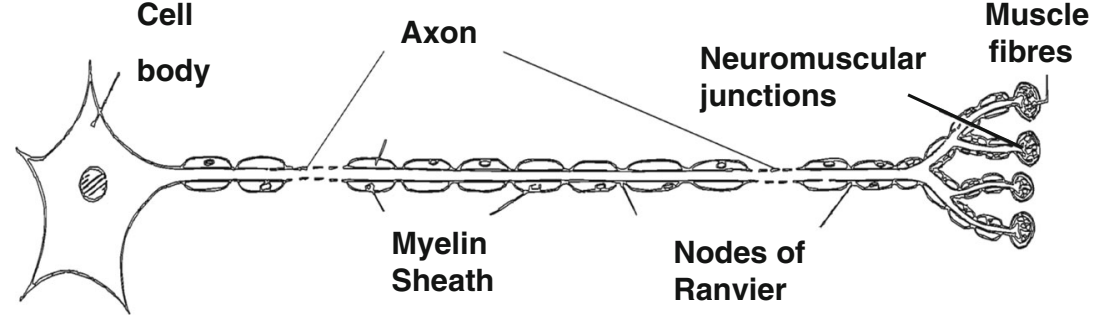

or lower leg. Anatomic studies have been performed where an assumption was made that $40 \%$ to $60 \%$ of large-diameter myelinated fibers are alpha motor neurons [6-8], and the number of motor units was determined. Using these histologic methods the flexor digiti minimi muscle in the hand was calculated to contain approximately 130 motor units [9]. Muscles, such as the eye, requiring fine motor control have a greater ratio of numbers of motor units to numbers of muscle fibers [10].

There are different types of motor units that, in turn, define the characteristics of the muscle fibers. Type 1 muscle fibers are efficient at using oxygen, more resistant to fatigue, are used for continuous extended muscle contraction, and are the first to be recruited with voluntary muscle contraction. Type 2 fast-twitch muscle fibers use anaerobic metabolism, are used in generating short bursts of contraction, and are activated at maximal force of contraction. These type 2 fibers are preferentially assessed with methods that use maximum force analysis [11]. The conventional view is that electrical stimulation progressively activates larger-diameter motor neurons, and smaller motor neurons have the lowest threshold with voluntary contraction, although this does not necessarily apply after nerve injury $[12,13]$.

The integration of motor units in motor control appears highly complex $[2,14,15]$. It is likely that the motor pathway should be considered as a network from the gamma motor neuron in the cortex through to the associated muscle fibers, with multiple levels of neuronal feedback.

\section{Need for Assessment of Motor Units}

The assessment of motor units is problematic in disorders of the motor neuron. It is not possible to biopsy motor nerves to measure motor unit numbers and even in postmortem studies, where tissue is available, it is difficult to distinguish largefiber motor and sensory axons. There is significant variability between different individuals and between different muscles. The variability in strength between and within individual muscles has meant that there is no single reliable measure for assessing muscle strength. The Medical Research Council grading is a gross estimate using a 5-point scale [16]. Modifications to standardize muscles with a composite score have been published [17], and manual strength testing has been used in recent trials [18]. Hand-held dynamometry (HHD) using grip strength to assess voluntary isometric strength has been developed for practical use and was superior to an ALS score and manual scores [19]. HHD was used in the 2 recent large international phase II-III ALS clinical trials [20, 21], as well as other recent smaller studies [22], with HHD inferior to the revised ALS functional rating scale-revised (ALSFRS-R) but better than vital capacity [23]. The methodology for HHD and manual testing has become standardized but nonlinear decline in muscle strength due to collateral reinnervation, the use of muscles such as finger flexion (which is relatively preserved in ALS), and the wide variability in normal muscle strength (whereby the strength of the manual tester can influence the result), are potential limitations of the muscle strength testing methods.

In addition, measurement of weakness is not a sufficient measure of the number of motor units because weakness due to denervation can be compensated for by collateral reinnervation if there are remaining normal motor axons supplying denervated muscle [24-26]. Collateral reinnervation after denervation is an ongoing process and accounts for the finding on muscle biopsies of fiber-type grouping with loss of the normal checkerboard pattern, and for an increased size of the motor unit action potentials on electromyography (EMG). It occurs with progressive incomplete denervation $[26,27]$, in nonprogressive diseases exemplified by poliomyelitis which has very large motor units, and to a lesser extent with normal aging. Collateral reinnervation can compensate for the loss of at least $50 \%$ of the motor neuron pool [25], and probably occurs to some degree until only $5 \%$ of the motor unit pool remains [27, 28]. From collateral reinnervation, synaptic sprouts occur such that immature reinnervating end plates form unstable connections with muscle, creating motor unit instability [29]. The effective result of collateral reinnervation is the nonlinear preservation of muscle strength despite falling motor unit number.

\section{Electromyographic Assessment of Motor Units}

Standard electrophysiology using nerve conduction studies measures a muscle compound muscle action potential (CMAP) - usually the amplitude, latency, and the F-wave response are considered. The size of CMAP of commonly tested 
muscles declines with progression of ALS, and a summed score of CMAP has been used in a small clinical study [30]. However, there is a notable variation in normal values for the CMAP [31], and limited reproducibility with retesting (due to factors such as electrode placement, temperature, and noise).

EMG is a standard tool for assessing denervation and reinnervation and is crucial for diagnosing ALS. With inspection of the EMG, different motor units can be identified and there have also been a number of computerized motor unit analysis techniques to assess firing of multiple motor units, most commonly using needle EMG, and also using surface recordings. The motor unit territory can be assessed by needle EMG [32], and the decomposition and quantitation of the EMG signal was developed by Stashuk [33] as a practical method of assessing micro- and macro-EMG signals. Motor unit morphology can also be assessed using surface electrodes by using high-density grids [34].

\section{Estimation of the Number of Motor Units}

In an attempt to develop a biomarker for the loss of motor units, the field of motor unit number estimates (MUNE) was developed in the 1970s [3]. Most of the electrophysiology methods have studied the thenar and hypothenar muscles supplied by the median or ulnar nerves, and, to a lesser extent, the extensor digitorum brevis or tibialis anterior muscles supplied by the peroneal nerve, although there are many small studies of other nerve, muscle combinations. More than 7 MUNE methods have been published [35-42]. These can be divided into 3 groups: 1) methods developed $>15$ years ago where the methodology has been validated but the method is relatively inactive or used in few centers; 2) active methods that are used in multiple centers with validated methodology; 3) active methods that are used in few centers/research centers and the methodology requires further validation.

These will now be discussed in turn.

\section{Established MUNE Methods}

\section{Established MUNE Methods Based on Electrical Stimulation}

Previous electrical MUNE methods generally relied on the calculation of an average size of a motor unit, which could then be divided into the total CMAP to calculate a motor unit number estimate. Gradually increasing the size of the stimulus intensity to recruit additional motor units (incremental method), stimulating the nerve at different points to sample different motor axons [multiple point stimulation (MPS)], using the F-wave for analysis, or using statistical analysis of motor unit firing (statistical methods), have been used to obtain the average MU size [35-38, 40, 41]. Values of 200-300 motor units for the hand muscles, with reasonable test-retest reliability, were obtained with the incremental and MPS methods. The major limitation of the original incremental MUNE method was alternation whereby stimuli of the same strength could activate different combinations of individual motor units. Stein and Yang [43] estimated that the probability of alternation was $>65 \%$ when 10 motor units are activated by graded incremental stimulation. This led to the development of the MPS method whereby a series of low-intensity stimuli were given in different sites of a peripheral nerve. The statistical MUNE method was also developed by Daube [40] to account for the phenomenon of alternation using Poisson statistics and this method gives smaller MUNE values of approximately 100 to 150 obtained from hand muscles. More complex statistical modifications such as the weighted-average method were developed, but the statistical methods have not progressed beyond the research setting [41]. The statistical method appears limited when individual large motor units are measured at a particular stimulus level rather than a Poisson distribution of motor units. The incremental, MPS and statistical methods have all shown reasonable test-retest reproducibility and appear sensitive to disease progression [3]. Currently, the incremental and MPS methods have been combined in the multipoint incremental method described in the next subsection.

\section{Established MUNE Methods Based on Needle or Surface EMG Methods}

At a similar time to when the statistical methods were being devised, methods based on the size and pattern of the EMG signal (spike-triggered averaging) were also developed. These methods enabled more proximal muscles to be studied [44, 45]. Modifications such as decomposition spike-triggered averaging used a computerized algorithm to analyze multiple individual motor unit potentials. The aim of these methods was to calculate a mean motor unit size that can be divided into the total CMAP to determine a MUNE with reasonable reliability [3]. The need for specialized software and operator input has somewhat limited widespread applicability.

\section{Active Validated Methods of Assessing Motor Unit Number}

It remains clear that a biomarker for ALS is needed and that electrophysiological methods offer an opportunity to produce a direct measurement of motor axon loss, a key feature of disease [46]. At present, 2 methods are actively used in different centers. These are the Motor Unit Number Index (MUNIX) method, which is used largely in Europe and Asia, and the multipoint incremental method, which is favored in North America. 


\section{MUNIX}

This method, developed by Nandedkar et al. [47], is noninvasive with standard nerve conduction studies (NCS) electrodes typically placed over the median or ulnar innervated hand muscles. The maximal CMAP is carefully determined. A gradual increase in force creates an EMG surface interference pattern (SIP). Five different levels of increasing voluntary effort are repeatedly tested and retested to determine the SIP. The SIP and CMAP are imported to propriety software. The power and area of the maximal CMAP and each SIP are determined. An index is determined based on an ideal case motor unit count defined as the ratio of the maximum $\mathrm{M}$-wave power to its area multiplied by the ratio of the SIP area to its power. Thus, each SIP level gives an area and ideal case motor unit count. A regression curve that defines the tested muscle is produced. Rather than rely on actual force measurements, a value is computed from a small-value $(20 \mathrm{mV} / \mathrm{ms})$ to determine an index value (MUNIX) from the established exponential fitting for that muscle. There are some arbitrary criteria imposed to accept a SIP. A motor unit size index can be similarly obtained by dividing the total CMAP by the MUNIX [48, 49].

Recently longer-term studies using MUNIX have being performed, with extension of the technique to the tibialis anterior and trapezius muscles, and to earlier stages of disease [50-54]. Standardization across multiple centers has been published where 6 proximal and distal muscles were assessed over 15 months from 3 different centers [55]. The software for MUNIX is becoming more freely available on the standard Viking and Synergy EMG machines and increasing publications from different centers across the globe will increase its acceptability for use in a clinical trial. It is the method used in most centers across the globe, with 39 publications in the last 3 years and is probably the most widely accepted method for assessing motor units [56].

\section{Multiple Point Incremental Stimulation}

In North America, this MUNE method remains in active use and combines the incremental and MPS methods, where a small number of incremental motor units are studied from different sites along the nerve using standardized methodology [57]. The method was devised to overcome the problem of bias from alternation, which is the overlapping size of different motor units due to probabilistic firing at submaximal stimulus intensities. The method appears reliable and sensitive to disease progression and could be applied across multiple centers $[57,58]$. Recently, a study from Poland demonstrated utility of this method from the first dorsal interosseous muscle when compared with other clinical parameters [59], and the method was applied to a study of carpal tunnel syndrome [60]. The multipoint incremental method has also been used with high-density surface EMG [61].
The advantages of the multipoint incremental stimulation method are that it does not require multiple supramaximal stimuli, which are uncomfortable, and it is relatively quick at 5 minutes per muscle. Comparisons with healthy controls and longitudinal studies have been performed and the method appears reliable in slowly progressive denervation [57]. At present, this method is actively used in a few centers but with fewer recent publications than the MUNIX method.

The challenges for both of these MUNE methods are the wide variability in normal values, some operator input is required to determine the maximal CMAP and whether to accept artifact, and the utility across different stages of ALS when there can be issues such as very low CMAP or rapid progression with unstable motor units. In addition a method that can be used in clinical trials needs to be easily applicable across multiple centers.

\section{Electrophysiology Methods Requiring Further Validation}

MUNE methods have not achieved widespread applicability and this has led to the development of other recent indirect electrophysiological methods for assessing motor units. A number of methods have been developed for application to ALS and appear promising.

\section{Neurophysiology Index}

The Neurophysiology Index, developed by Swash and de Cavalho [62, 63], relies on the formula of the CMAP size/ latency $\times \mathrm{F}$-wave persistence, and was conceived as a practical measure utilizing typical measures obtained with standard nerve conduction studies. It has largely been studied in the ulnar nerve. There are no longer-term studies in ALS and limited recent publications.

\section{Split Hand Index}

The recent identification of the split hand offers potential as an ALS biomarker [64]. The split hand index (SHI) is calculated using the formula: $\mathrm{SHI}=\mathrm{APB} \mathrm{CMAP} \times \mathrm{FDI} \mathrm{CMAP} / \mathrm{ADM}$ CMAP [65], where APB is the abductor pollicis brevis, FDI is the first dorsal interosseous, and ADM is the abductor digiti minimi. There remains debate about whether the split hand phenomenon reflects peripheral or central mechanisms. Arguments for the peripheral mechanism note the different excitability properties in the respective peripheral nerves. A central explanation has support from evolutionary concepts where the thumb movements, in particular pincer grip, are specific to humans, and corticomotoneuron studies of the pincer grip that show upper motor neuron integrity is required for the precision movement [66]. The SHI is helpful clinically in that finding a value $<5.2$ supports ALS and it is easy to perform. However, it is not specific to ALS and there remains a 
need to validate the index across multiple centers and from the whole spectrum of clinical presentations of ALS. The SHI has recently been applied to MUNIX [67].

\section{Electrical Impedance Myography}

Electrical impedance myography (EIM) developed by a single laboratory involves a set of electrodes placed over the belly of the muscle [68, 69]. A small, high-frequency electrical current is applied and the surface voltage can then be measured. The values represent the properties of the underlying tissue with changes in muscle morphology due to factors such as fibrosis, denervation, or edema.

Typically, 4 or more voltage-sensing surface electrodes are placed over the belly of the muscle. A single or multifrequency current is applied with reference to far-field electrodes. The published results show high reliability and sensitivity to disease progression. Rutkove et al. [70] showed that the rate of decline in 50 patients with ALS over 6 months was similar to that of the ALSFRS-R and HHD. This method has the advantage that more proximal muscles can be studied and muscle contraction/nerve stimulation is not required. EIM is being used in a pilot study of lumbar stem cell therapy [71]. However, the parameters for use in a multicenter clinical trial still need to be defined, and the method is used in only a few centers.

\section{The CMAP Scan}

The CMAP scan involves gradual increments in stimulus intensity with the subsequent measurement of the CMAP size [72-76]. It is attractive because it studies all of the motor units in a muscle, and has been shown to measure effectively the decline in motor unit number across a range of different rates of disease progression [74]. However, at present, applications either require off-line analysis (Bayesian MUNE) [73, 74], or have not been validated across the different stages of disease progression [77].

\section{Other Methods for the Assessment of Motor Units}

The need for objective outcome measures that can be reliably quantified and responsive to clinical deficit and disease progression has led to a search for useful quantitative imaging techniques [78].

\section{Magnetic Resonance Imaging}

Recently, magnetic resonance imaging was applied to chronic denervation in inherited neuropathy. The muscle fat fraction was serially assessed and showed correlation with functional measures [79]. Using diffusion tractography, fractional anisotropy was shown to correlate with axon pathology in ALS $[80,81]$. The methods need to be standardized and reproducible across different centers and, in general, magnetic resonance imaging methods have mainly been applied to upper motor neuron dysfunction in ALS.

\section{Ultrasound}

Ultrasound has been studied in more detail and in patients with ALS. Muscle thickness and echo intensity have been studied with echo intensity correlating with survival in one study [82]. The cross-sectional area has been studied from the median and ulnar nerves showing a decline in longitudinal studies [83]. The role of ultrasound in detecting fasciculations has been highlighted [84]. The change may not correlate as well with other measures of functional decline [85], and validated multicenter studies are needed.

\section{Peripheral Nerve Excitability}

Excitability testing is useful for showing changes in disease compared with controls using the strength-duration time constant and threshold electrotonus [86]. Values for assessing motor units have not been determined and there is a requirement for specialized equipment. However, the ability to study the excitability of single motor units is potentially very promising [87].

\section{ALS Clinical Trials}

The assessment of motor units is an attractive endpoint for clinical trials of ALS because it is directly related to the pathology of disease, and MUNE methods consistently show correlation with clinical features at baseline and with disease progression. The commonly used surrogate biomarkers of disease progression in the ALS clinic include the forced vital capacity and the ALSFRS-R [88, 89], and these have been widely used in clinical trials because they show a reasonably linear decline [90]. Other simple clinical measures are also being proposed which require validation [91]. However, a measure that is targeted at the underlying pathology (loss of motor units) is needed for assessing the phenotypic heterogeneity of ALS where patients have varying degrees of involvement of upper and lower motor neurons/axons. Patients with ALS have differing rates of disease progression and while average survival is typically 2-3 years, a tail of long survivors occurs, partly due to disease pathology and also due to patient choices regarding respiratory support [88]. The severity of lower motor neuron involvement in ALS appears to be particularly relevant for survival [92], and therefore is an important measure to be evaluated in clinical trials. 
The pattern of loss of motor units with disease progression is uncertain, with some groups finding a linear decline [90], and others a model of disease death favoring an exponential process of cell death [93]. A linear decline allows a more practical comparison of different stages of disease progression. Besides assessing rate of motor unit loss, MUNE has been proposed as a means of stratifying patients according to rate of progression [94].

Electrophysiological methods remain the most promising candidate as a biomarker of lower motor neuron loss, but no method has achieved widespread assessment nor consistent use in large, multicenter clinical trials. The statistical MUNE method was used in the unsuccessful multicenter creatine study, and it became clear that the method was limited as it does not account for motor unit variability as seen as advanced disease [95]. Other methods of motor unit assessment have been used in single trials of memantine [96], but methods of assessing motor units were not used in 2 recent, large international phase IIb multicenter studies [20, 21], nor other recent exploratory phase II studies [22, 97, 98]. The discussion of MUNE at recent meetings has been limited; for example, MUNIX was the only method discussed at the recent International ALS/Motor Neurone Disease Symposium in December 2015 [99].

Both the multipoint incremental motor unit number estimation and the MUNIX methods have been proposed as suitable outcome measures in ALS trials. Both are relatively easy to perform across different centers and different hand and foot muscles can be studied. The multipoint incremental method has the advantage that it is conceptually easy to understand and can be performed on standard electrophysiology machines but requires a degree of operator involvement, while MUNIX can also be performed on standard machines (that have the software installed) and has the advantage that it does not require electrical stimulation and is reasonably automated with rapid data collection. A degree of operator input is required for both methods.
The requirements for the assessment of motor units in an international multicenter clinical trial would appear to be 1) reliability of the results, 2 ) ease of data collection preferably by a technician or research assistant; 3 ) established standardized muscles and protocols; and 4) methods sensitive to disease pathology and progression.

The candidates for electrophysiological biomarkers in comparison with other measures are summarized in Table 1. The ability to show disease progression at equal to or superior rates of decline than the established ALFRS-R and manual/ isometric strength has been a key feature supporting electrophysiological methods both old [100-102] and new [55].

\section{MUNE in Other Neuromuscular Diseases and Normal Aging}

Other diseases with denervation are attractive for study using MUNE and in these the influence of motor unit instability inherent to ALS is less of a problem [103]. Inherited peripheral neuropathies have been studied with significantly lower MUNE values being found in Charcot-Marie-Tooth (CMT) hereditary neuropathies type 1A, type X, and type 2 in distal ulnar nerveinnervated muscles compared with control values. There were also lower values in more proximal muscles (biceps brachii), correlating with axonal loss, but these findings were less significant than the changes in distal muscles [104, 105]. Recently MUNIX has been applied to the study of demyelinating neuropathies [106], and has an advantage over older MUNE methods that are limited by the higher stimulus intensities required in some hereditary motor neuropathies.

Normal aging has also been studied with MUNE. Healthy adults over 60 years of age demonstrate reductions of $50 \%$ or greater in both distal (thenar, hypothenar) and more proximal muscles (biceps brachii, tibialis anterior, soleus) when compared with their younger counterparts. One study, using decomposition-enhanced STA showed that "very elderly
Table 1 Comparison of motor unit biomarkers that are used in amyotrophic lateral sclerosis (ALS)

\begin{tabular}{lllll}
\hline Method & Reliability* & $\begin{array}{l}\text { Ease of data } \\
\text { collection }\end{array}$ & $\begin{array}{l}\text { Standardized } \\
\text { protocols }\end{array}$ & Sensitive to progression \\
\hline ALSFRS-R [89, 90] & 0.77 & ++ & +++ & Approx. 1-2 \%/month \\
HHD [23] & 0.63 & ++ & + & Not stated \\
Manual muscle [17] & 0.67 & ++ & + & $1.0-1.5 \% /$ month \\
MUNIX [55] & 0.80 & + & + & $2.4-4.2 \% /$ month \\
MIM [57] & $9.5 \% \dagger$ & + & + & $3 \% /$ month \\
Imaging & Not established & ++ & No & Not established \\
\hline
\end{tabular}

The ALS functional rating scale-revised (ALSFRS-R) is a global measure. HHD = hand-held dynamometry; MUNIX = Motor Unit Number Index; MIM = multipoint incremental

*The coefficient of variation/correlation coefficient is not standard across the methods

$\dagger$ Test-retest variability in normal subjects 
men" (mean age $>80$ years) had even greater motor unit loss than "older men" (mean age 66 years) [107]. Motor unit loss associated with aging is a significant factor leading to agerelated reductions in muscle mass, strength, and power (often referred to as "sarcopenia").

Spinal muscular atrophy is a slowly progressive disorder usually characterized by proximal greater than distal weakness, so MUNE methods developed from distal muscles have been less applicable but earlier MUNE methods have been used [108, 109]. MUNE has been applied to compression neuropathies and postpolio syndrome and has shown correlations with disease severity $[110,111]$.

\section{Conclusion}

In 2016, there remains a need for a lower motor neuron biomarker of disease progression. In the absence of reliable imaging, blood, or respiratory biomarkers, many centers across Europe, the Americas, Asia, and Australia remain active in the area of assessment of motor unit numbers. For use in a clinical trial, a biomarker of motor units will need to be sensitive to disease pathology, reproducible, and have utility at many clinical centers. At present, researchers studying the MUNIX and multipoint incremental methods are the most active, but it remains to be seen whether this will be translated into use in an international clinical trial.

Required Author Forms Disclosure forms provided by the authors are available with the online version of this article.

\section{References}

1. Sherrington CS. Some functional problems attaching to convergence. Proc R Soc Lond Ser B 1929;105:332-362.

2. de Carvalho M, Swash M. Lower motor neuron dysfunction in ALS. Clin Neurophysiol 2016;127:2670-2681.

3. Gooch CL, Doherty TJ, Chan KM, et al. Motor unit number estimation: a technology and literature review. Muscle Nerve 2014; 50:884-893.

4. McNeil CJ, Doherty TJ, Stashuk DW, Rice CL. Motor unit number estimates in the tibialis anterior muscle of young, old and very old men. Muscle Nerve 2005;31:461-467.

5. Bromberg M. Updating motor unit number estimation (MUNE). Clin Neurophysiol 2007;118:1-8.

6. Santo Neto H, Filho JM, Marques MJ. Number and size of motor units in thenar muscles. Clin Anat 2004;17:308-311.

7. Feinstein B, Lindegard B, Nyman E, Wohlfart G. Morphologic studies of motor units in normal human muscles. Acta Anat 1955;23:127-142.

8. Boyd IA, Davey MR. Composition of peripheral nerves. Livingstone, Edinburgh 1968; pp 2-57.

9. Santo Neto H, De Carvelho VC, Marques MJ. Estimation of the number and size of human flexor digiti minimi muscle motor units using histological methods. Muscle Nerve 1998;21:112-114.
10. Buchtal, FH, Schmalbruch H. Motor unit of mammalian muscle. Physiol Rev 1980;60: 90-142.

11. Farina D, Fosci M, Merletti R. Motor unit recruitment strategies investigated by surface EMG variables. J Appl Physiol 2002;92: 235-247.

12. Kayagil TA, Grimes, JP, Grill WM. Mechanisms underlying reversal of motor unit activation order in electrically evoked contractions after spinal cord injury. Muscle Nerve 2008;37:210-218.

13. Thomas CK, Nelson G, Than L, Zijdewind I. Motor unit activation order during electrically evoked contractions of paralyzed of partially paralyzed muscles. Muscle Nerve 2002;25: 797-804.

14. Monti RJ, Roy RR, Edgerton VR. Role of motor unit structure in defining function. Muscle Nerve 2001;24:848-866.

15. Eisen A, Weber M. The motor cortex and amyotrophic lateral sclerosis. Muscle Nerve 2001;24:564-573.

16. Medical Research Council. Aids to the examination of the peripheral nervous system, Memorandum no. 45, Her Majesty's Stationery Office, London, 1981.

17. Great Lakes Study Group. A comparison of muscle strength testing techniques in amyotrophic lateral sclerosis. Neurology 2003;61:1503-1507.

18. Andres PL, Skerry LM, Munsat TL, et al. Validation of a new strength measurement device for amyotrophic lateral sclerosis clinical trials. Muscle Nerve 2012;45:81-85.

19. Andres PL, Skerry LM, Thornell, B, et al. A comparison of three measures of disease progression in ALS. J Neurol Sci 1996;139: 64-70.

20. Cudkowicz ME, van den Berg LH, Shefner JM, et al. Dexpramipexole versus placebo for patients with amyotrophic lateral sclerosis (EMPOWER): a randomised, double-blind, phase 3 trial. Lancet Neurol 2013;12:1059-1067.

21. GlaxoSmithKline. Study of Ozanezumab (GSK1223249) versus placebo in the treatment of amyotrophic lateral sclerosis. Available at: https://clinicaltrials.gov/ct2/show/NCT01753076. Accessed 14 May 2016.

22. Cudkowicz ME, Shefner JM, Schoenfeld DA, et al. A randomized, placebo-controlled trial of topiramate in amyotrophic lateral sclerosis. Neurology 2003;61:456-464.

23. Shefner JM, Liu D, Leitner ML, et al. Quantitative strength testing in ALS clinical trials. Neurology 2016;87:617-624.

24. Wohlfart G. Collateral regeneration in partially denervated muscles. Neurology 1958;8:175-180.

25. Emeryk-Szajewska B, Kopec J, Karwanska A. The reorganization of motor units in motor neurone disease. Muscle Nerve 1997;20: 306-315.

26. Bjornskov E, Norris F, Mower-Kuby J. Quantative axon terminal and end-plate morphology in amyotrophic lateral sclerosis. Arch Neurol 1984;41:527-530.

27. Hansen S, Ballantyne JP. A quantitative electrophysiological study of motor neurone disease. J Neurol Neurosurg Psychiatry 1978;41:773-783.

28. Pinelli P, Pisano F, Ceriani F, Miscio G. EMG evaluation of motor neuron sprouting in amyotrophic lateral sclerosis. Ital J Neurol Sci 1991;12:359-367.

29. Maselli RA, Wollman RL, Leung C, et al. Neuromuscular transmission in amyotrophic lateral sclerosis. Muscle Nerve 1993;16: 1193-1203.

30. Askmark H, Aquilonius SM, Gillberg PG, et al. Functional and pharmacokinetic studies of tetrahydroaminoacridine in patients with amyotrophic lateral sclerosis. Acta Neurol Scand 1990;82: 253-258.

31. Krarup C, Buchtal F. Conduction studies in peripheral nerve. Neurobehav Toxicol Teratol 1985;7:319-323.

32. Buchthal F, Erminio F, Rosenfalck P. Motor unit territory in different human muscles. Acta Physiol Scand 1959;45:72-87. 
33. Stashuk DW. Decomposition and quantitative analysis of clinical electromyographic signals. Med Eng Phys 1999;21:389-404.

34. Lapatki BG, Van Dijk JP, Jonas IE, Zwarts MJ, Stegeman DF. A thin, flexible multi-electrode grid for high-density surface EMG. J Appl Physiol 2004;96:327-336.

35. McComas AJ, Fawcett PR, Campbell MJ, Sica RE. Electrophysiological estimation of the number of motor units within a human muscle. J Neurol Neuropsych Psychiatry 1971;34:121-131

36. Brown WF. A method for estimating the number of motor units in thenar muscles and the changes in motor unit count with ageing. J Neurol Neurosurg Psychiatry 1972;35:845-852.

37. Doherty TJ, Komori T, Stashuk DW, Kassam A, Brown WF. Physiological properties of single thenar motor units in the Fresponse of younger and older adults. Muscle Nerve 1994;17: 860-872.

38. Bromberg MB, Forshew DA, Nau KL, et al. Motor unit number estimation, isometric strength and electromyographic measures in amyotrophic lateral sclerosis. Muscle Nerve 1993;16:1213-1219.

39. Slawnych M, Laszlo C, Herschler C. Motor unit estimates obtained using the new "MUESA" method. Muscle Nerve 1996;19: 626-636.

40. Daube JR. Estimating the number of motor units in a muscle. J Clin Neurophysiol 1995;12:585-594.

41. Simmons Z, Epstein DK, Borg B, et al. Reproducibility of motor unit number estimation in individual subjects. Muscle Nerve 2001;24:467-473.

42. Blok JH, Visser GH, De Graaf S, Zwarts MJ, Stegeman DF. Statistical motor number estimation assuming a binomial distribution. Muscle Nerve 2005;31:182-191.

43. Stein RB, Yang JF. Methods for estimating the number of motor units in human muscles. Ann Neurol 1990;28:487-495.

44. Boe SG, Stashuk DW, Doherty TJ. Motor unit number estimation by decomposition-enhanced spike-triggered averaging: control data, test-retest reliability, and contractile level effects. Muscle Nerve 2004; 29:693-699.

45. Ives CT, Doherty TJ. Intra- and inter-rater reliability of motor unit number estimation and quantitative motor unit analysis in the upper trapezius. Clin Neurophysiol 2012;123:200-205.

46. Benatar M, Boylan K, Jeromin A, et al. ALS biomarkers for therapy development: state of the field and future directions. Muscle Nerve 2016;53:169-182.

47. Nandedkar SD, Barkhaus PE, Stalberg EV. Motor unit number index (MUNIX): principle, method, and findings in healthy subjects and in patients with motor neuron disease. Muscle Nerve 2010;42:798-807.

48. Neuwirth C, Nandedkar S, Stalberg E. Motor unit number index (MUNIX): a novel neurophysiological technique to follow disease progression in amyotrophic lateral sclerosis. Muscle Nerve 2010; 42: 379-384.

49. Nandedkar SD, Barkhaus PE, Stalberg EV. Reproducibility of MUNIX in patients with amyotrophic lateral sclerosis. Muscle Nerve 2011; 44:919-922.

50. Boekestein WA, Schelhaas HJ, van Putten MJ, et al. Motor unit number index (MUNIX) versus motor unit number estimation (MUNE): a direct comparison in a longitudinal study of ALS patients. Clin Neurophysiol 2012;123:1644-1649.

51. Furtula J, Johnsen B, Christensen PB, et al. MUNIX and incremental stimulation MUNE in ALS patients and control subjects. Clin Neurophysiol 2013;124:610-618.

52. Fathi D, Mohammadi B, Dengler R, et al. Lower motor neuron involvement in ALS assessed by motor unit number index (MUNIX): long-term changes and reproducibility. Clin Neurophysiol 2016;127:1984-1988.
53. Stein F, Kobor I, Bogdahn U, Schulte-Mattler WJ. Toward the validation of a new method (MUNIX) for motor unit number assessment. J Electromyogr Kinesiol 2016;27:73-77.

54. Fukada K, Matsui T, Furuta M, et al. The Motor Unit Number Index of subclinical abnormality in amyotrophic lateral sclerosis. J Clin Neurophysiol 2016 May 7

55. Neuwirth C, Barkhaus PE, Burkhardt C, et al. Tracking motor neuron loss in a set of six muscles in amyotrophic lateral sclerosis using the Motor Unit Number Index (MUNIX): a 15-month longitudinal multicentre trial. J Neurol Neurosurg Psychiatry 2015;86:1172-1179.

56. Swash M, Kiernan MC. Measuring change in amyotrophic lateral sclerosis. J Neurol Neurosurg Psychiatry 2015;86:1169-1170.

57. Shefner JM, Watson ML, Simionescu L, et al. Multipoint incremental motor unit number estimation as an outcome measure in ALS. Neurology 2011;77:235-241.

58. Jagtap SA, Kuruvilla A, Govind P, et al. Multipoint incremental motor unit number estimation versus amyotrophic lateral sclerosis functional rating scale and the medical research council sum score as an outcome measure in amyotrophic lateral sclerosis. Ann Indian Acad Neurol 2014;17:336-339.

59. Gawel M, Zalewska E, Lipowska M, et al. Motor unit number estimation as a complementary test to routine electromyography in the diagnosis of amyotrophic lateral sclerosis. J Electromyogr Kinesiol 2016;26:60-65.

60. Yilmaz O, Sunter G, Salcini C, et al. Motor-unit number estimation is sensitive in detecting motor nerve involvement in patients with carpal tunnel syndrome. J Clin Neurol 2016;12:166-171.

61. van Dijk JP, Blok JH, Lapatki BG, et al. Motor unit number estimation using high-density surface electromyography. Clin Neurophysiol 2008;119:33-42.

62. Swash M, de Carvalho M. The Neurophysiological Index in ALS. Amyotroph Lateral Scler Other Motor Neuron Disord 2004;5(Suppl. 1):108-110.

63. de Carvalho M, Swash M. Nerve conduction studies in amyotrophic lateral sclerosis. Muscle Nerve 2000;23:344-352.

64. Kuwabara S, Mizobuchi K, Ogawara K, Hattori T. Dissociated small hand muscle involvement in amyotrophic lateral sclerosis detected by motor unit number estimates. Muscle Nerve 1999;22: 870-873.

65. Menon P, Kiernan MC, Yiannikas C, Stroud J, Vucic S. Split-hand index for the diagnosis of amyotrophic lateral sclerosis. Clin Neurophysiol 2013;124:410-416.

66. Eisen A Kuwabara S. The split hand syndrome in amyotrophic lateral sclerosis. J Neurol Neurosurg Psychiatry 2012;83:399-403.

67. Kim DG, Hong YH, Shin JY, et al. Split hand phenomenon in amyotrophic lateral sclerosis: a motor unit number index study. Muscle Nerve 2016;53:885-888.

68. Rutkove SB. Electrical impedance myography: Background, current state, and future directions. Muscle Nerve 2009;40:936-946.

69. Rutkove SB, Caress JB, Cartwright MS, et al. Electrical impedance myography as a biomarker to assess ALS progression. Amyotroph Lateral Scler Other Motor Neuron Disord 2012;13: 439-445.

70. Rutkove SB, Caress JB, Cartwright MS, et al. Electrical impedance myography correlates with standard measures of ALS severity. Muscle Nerve 2014;49:441-443.

71. Glass JD, Boulis NM, Johe K, et al. Lumbar intraspinal injection of neural stem cells in patients with amyotrophic lateral sclerosis: results of a phase I trial in 12 patients. Stem Cells 2012;30:1144 1151.

72. Blok JH, Ruitenberg A, Maathuis EM, Visser GH. The electrophysiological muscle scan. Muscle Nerve 2007;36:436-446.

73. Ridall PG, Pettitt AN, Henderson RD, McCombe PA. Motor unit number estimation- a Bayesian approach. Biometrics 2006;62: $1235-1250$. 
74. Henderson RD, Ridall PG, Hutchinson NM, Pettitt AN, McCombe PA. Bayesian statistical MUNE method. Muscle Nerve 2007;36:206-213.

75. Sleutjes BT, Montfoort I, Maathuis EM, et al. CMAP scan discontinuities: automated detection and relation to motor unit loss. Clin Neurophysiol 2014;125:388-395.

76. Maathuis EM, Drenthen J, van Doorn PA, Visser GH, Blok JH. The CMAP scan as a tool to monitor disease progression in ALS and PMA. Amyotroph Lateral Scler Frontotemporal Degener 2013;14:217-223.

77. Bostock H. Estimating motor unit numbers from a CMAP scan. Muscle Nerve 2016;53:889-896.

78. Fleckenstein JL. MRI of neuromuscular disease: the basics. Semin Musculoskelet Radiol 2000;4:393-419.

79. Forbes S, Willcocks RJ, Rooney WD, Walter GA, Vandenborne K. MRI quantifies neuromuscular disease progression. Lancet Neurol 2016;15;26-28.

80. Takagi T, Nakamura M, Yamada M, et al. Visualization of peripheral nerve degeneration and regeneration: monitoring with diffusion tensor tractography. Neuroimage 2009;44:884-892.

81. Staff NP, Amrami KK, Howe BM. Magnetic resonance imaging abnormalities of peripheral nerve and muscle are common in amyotrophic lateral sclerosis and share features with multifocal motor neuropathy. Muscle Nerve 2015;52:137-139.

82. Arts IM, Overeem S, Pillen S, Schelhaas HJ, Zwarts MJ. Muscle ultrasonography to predict survival in amyotrophic lateral sclerosis. J Neurol Neurosurg Psychiatry 2011;82:552-554.

83. Schreiber S, Dannhardt-Stieger V, Henkel D, et al. Quantifying disease progression in ALS using peripheral nerve sonography. Muscle Nerve 2016;54:391-397.

84. Arts IM, Overeem S. Pillen S, Schelhaas HJ, Zwarts MJ. Muscle changes in amyotrophic lateral sclerosis: a longitudinal ultrasonography study. Clin Neurophysiol 2011;122:623-628.

85. de Carvalho, M. Ultrasound in ALS: is it a sound method? Clin Neurophysiol 2015;126: 820-827.

86. Burke D, Kiernan MC, Bostock H. Excitability of human axons. Clin Neurophysiol 2001;112:1575-1585.

87. Kudina LP, Andreeva RE. Excitability properties of single human motor axons: are all axons identical? Front Cell Neurosci 2014;8:85.

88. Kiernan MC, Vucic S, Cheah BC, et al. Amyotrophic lateral sclerosis. Lancet 2011;377:942-955.

89. Cedarbaum JM, Stambler N, et al. The ALSFRS-R: A revised ALS functional rating scale that incorporates assessments of respiratory function. J Neurol Sci 1999;169:13-21.

90. Proudfoot M, Jones A, Talbot K, Al-Chalabi A, Turner MR. The ALSFRS as an outcome measure in therapeutic trials and its relationship to symptom onset, Amyotroph Lateral Scler Frontotemporal Degener 2016;17:414-425.

91. Lunetta C, Lizio A, Melazzini MG, Maestri E, Sansone VE. Amyotrophic Lateral Sclerosis Survival Score (ALS-SS): a simple scoring system for early prediction of patient survival. Amyotroph Lateral Scler Frontotemporal Degener 2016;17:93-100.

92. Devine MS, Ballard E, O'Rourke P, et al. Targeted assessment of lower motor neuron burden is associated with survival in amyotrophic lateral sclerosis. Amyotroph Lateral Scler Frontotemporal Degener 2016;17:184-190.

93. Baumann F, Henderson RD, Ridall G, Pettitt AN, McCombe PA. Quantitative studies of lower motor neuron degeneration in amyotrophic lateral sclerosis : evidence for exponential decay of motor unit numbers and greatest rate of loss at the site of onset. Clin Neurophys 2012;123:2092-2098.

94. Bowser R, Turner MR, Shefner J. Biomarkers in amyotrophic lateral sclerosis: opportunities and limitations. Nat Rev Neurol 2011;11;7:631-638.

95. Shefner. The use of statistical MUNE in a multicenter clinical trial. Muscle Nerve 2004;30:463-469.

96. de Carvalho M, Pinto S, Costa J, et al. A randomized, placebocontrolled trial of memantine for functional disability in amyotrophic lateral sclerosis. Amyotroph Lateral Scler 2010;11:456-460.

97. Weiss MD, Macklin EA, Simmons Z, et al. A randomized trial of mexiletine in ALS: Safety and effects on muscle cramps and progression. Neurology 2016;86:1474-1481.

98. Lenglet, T, Lacomblez, L, Abitbol, JL, et al. A phase II-III trial of olesoxime in subjects with amyotrophic lateral sclerosis Eur J Neurol 2014;21:529-536.

99. Neuwirth C. MUNIX detects presymptomatic loss in ALS patients. Presented at the ALS/MND symposium, Orlando 2015.

100. Mitsumoto, H, Ulug AM, Pullman SL, et al. Quantitative objective markers for upper and lower motor neuron dysfunction in ALS. Neurology 2007:68;1402-1410.

101. Felice, KJ. A longitudinal study comparing thenar motor unit number estimates to other quantitative tests in patients with amyotrophic lateral sclerosis. Muscle Nerve 1997;20:179-185.

102. Liu XX, Zhang J, Zheng JY, et al. Stratifying disease stages with different progression rates determined by electrophysiological tests in patients with amyotrophic lateral sclerosis. Muscle Nerve 2009;39:304-309.

103. Stålberg EV, Sonoo M. Assessment of variability in the shape of the motor unit action potential, the "jiggle," at consecutive discharges. Muscle Nerve 1994:17:1135-1144.

104. Bromberg MB, Svoboda KJ, Lawson VH. Counting motor units in chronic motor neuropathies. Exp Neurol 2003;184:S53-S57.

105. Lewis R, Li J, Fuerst D, Shy M, Krajewski K. Motor unit number estimate of distal and proximal muscles in Charcot-Marie-Tooth disease. Muscle Nerve 2003;28:161-167.

106. Paramanathan S, Tankisi H, Andersen H, Fuglsang-Frederiksen A. Axonal loss in patients with inflammatory demyelinating polyneuropathy as determined by motor unit number estimation and MUNIX. Clin Neurophysiol 2016;127:898-904.

107. Doherty T, Vandervoort A, Taylor A, Brown W. Effects of motor unit losses on strength in older men and women. J Appl Physiol 1993;74: 868-874.

108. Bromberg MB, Svoboda KJ. Motor unit number estimation in infants and children with spinal muscular atrophy. Muscle Nerve 2002;25:445-447.

109. Gawel M, Kostera-Pruszczyk A, Lusakowska A, et al. Motor unit loss estimation by the multipoint incremental MUNE method in children with spinal muscular atrophy-a preliminary study. Neuromuscul Disord 2015;25:216-221.

110. Nashed J, Hamilton-Wright A, Stashuk DW, Faris M, McLean L. Assessing motor deficits in compressive neuropathy using quantitative electromyography. J Neuroeng Rehabil 2010;7:39.

111. Chan KM, Amirjani N, Sumrain M, Clarke A, Strohschein FJ. Randomized controlled trial of strength training in post-polio patients. Muscle Nerve 2003;27:332-338. 